\title{
The endothelial glycocalix changes are associated with haemodynamic and metabolic responses in on-pump valve repair surgery
}

Ilyina YY, Izotova NN, Volkov DA, Yakovenko EA, Kuzkov WV, Kirov MY

Department of Anaesthesiology and Intensive Care Medicine, Northern State Medical University, Arkhangelsk, Russian Federation.

City Hospital \# 1 n. a. E. E. Volosevich, Arkhangelsk, Russian Federation.

\section{Background \& Goal}

The endothelial glycocalix system is an important protective regulator of vascular integrity, permeability, cell interactions, and endothelial activation. The perioperative endothelial glycocalix shedding can be associated with capillary leak, haemodynamic and metabolic disturbances, as well as increased postoperative morbidity.

The goal of this pilot study was to assess the endothelial glycocalix response in the delayed period after elective uncomplicated on-pump valve repair surgery.

\section{Methods}

Twenty-six adult patients scheduled for elective valvular interventions on cardiopulmonary bypass were enrolled into a single-centre prospective observational study.

The components of endothelial glycocalix including Heparan Sulfate Proteoglycan (HSPG) and Syndecan-1 (SYN1) were measured after the induction of anaesthesia, and at 6, and 24 hrs postoperatively (ELISA Kits for HSPG, SDC1, USA).

The haemodynamic variables, including cardiac index (CI), systemic vascular resistance index (SVRI), pulse pressure variations (PPV), arterial and venous blood gases, N-terminal pro brain natriuretic peptide (NT-proBNP), lactate, and venous glucose concentrations were measured perioperatively.

The statistical analysis was performed using Mann-Whitney U-test, ANOVA, Spearman's rho, and ROC-analysis. Data are presented as median $\left(25^{\text {th }}-75^{\text {th }}\right.$ percentiles). $p$ values $<0.05$ were regarded as statistically significant.

\section{Results \& Discussion}

The key haemodynamic and metabolic variables involved in the associations with endothelial glycocalix components are presented in Table 1. At 6 hrs postoperatively, cardiac index increased significantly compared with the induction of anaesthesia.

At 6 hrs after surgery, we observed a 16\% decrease in HSPG concentration from 6.13

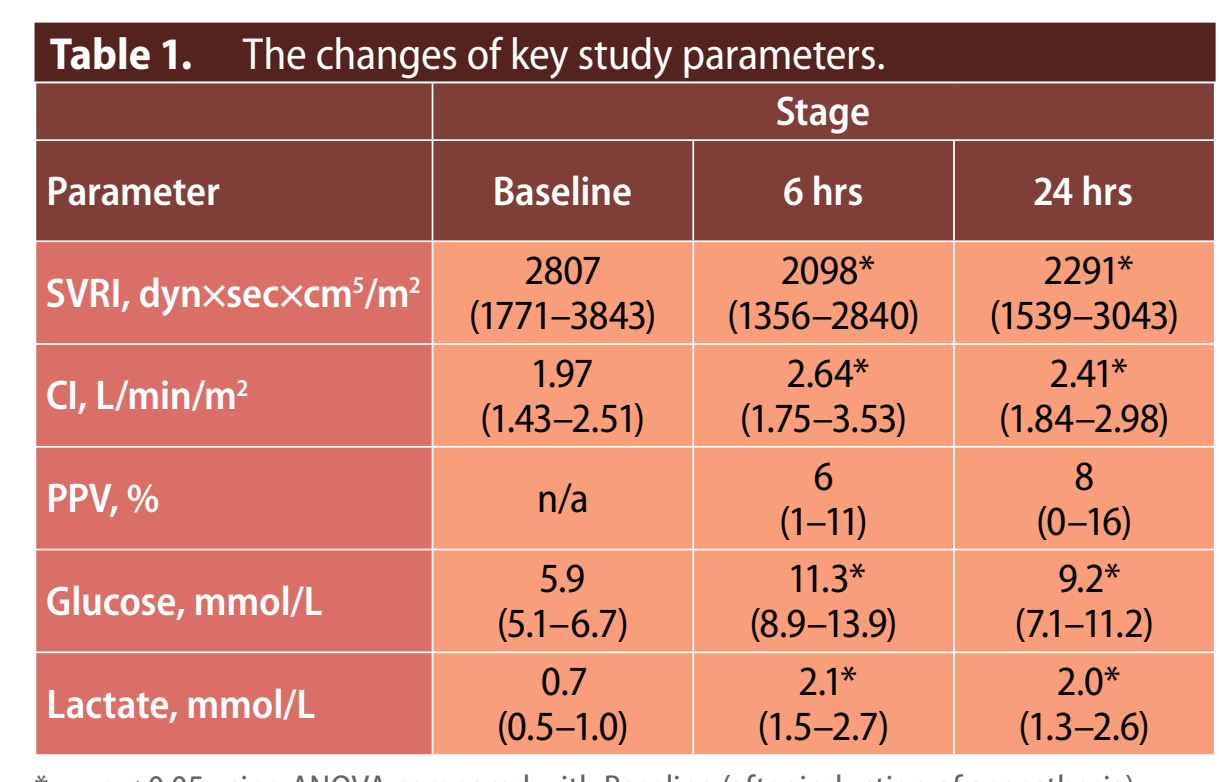

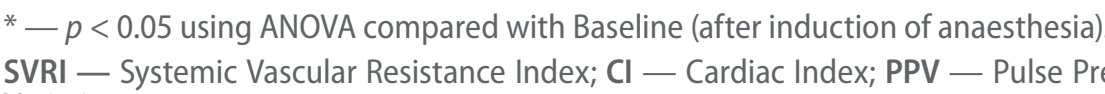
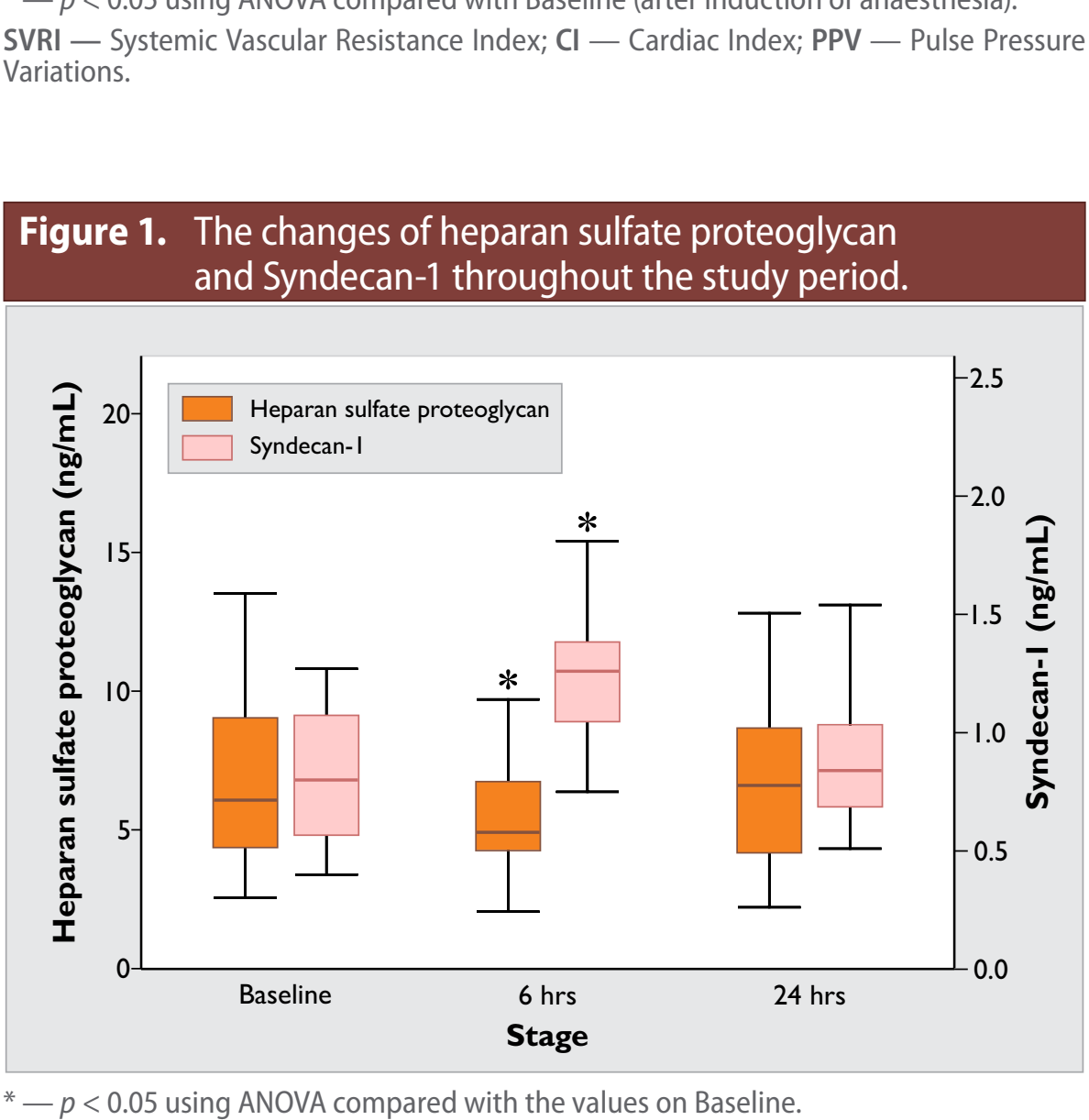

Figure 2. The correlation between baseline values of NTproBNP and heparan sulfate proteoglycan at 6 hrs postoperatively.

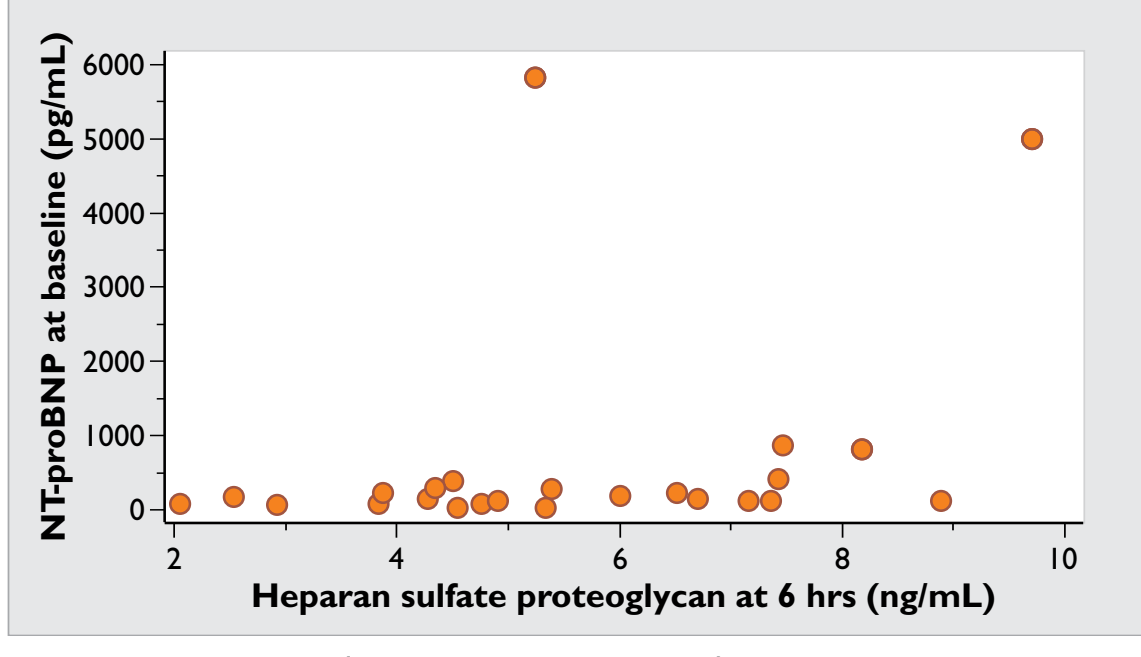

NT-proBNP — N-terminal pro Brain Natriuretic Peptide.
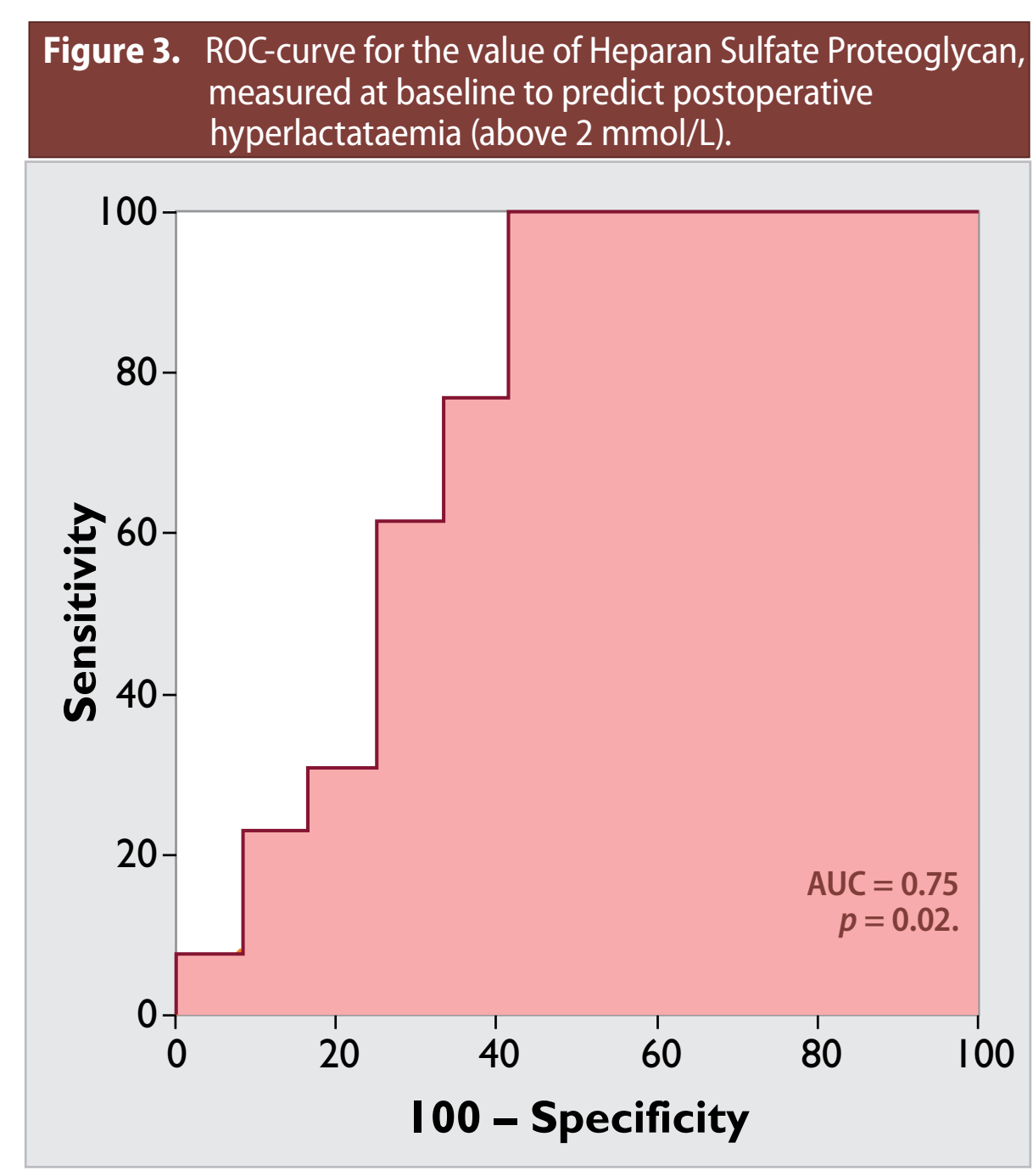

(4.20-9.04) ng/mL to $5.08(4.18-7.21) \mathrm{ng} /$ $\mathrm{mL}(p<0.01)$, while SYN1 significantly increased by $47 \%$ from $0.80(0.56-1.13) \mathrm{ng} /$ $\mathrm{mL}$ to $1.25(1.04-1.41) \mathrm{ng} / \mathrm{mL}(p<0.001)$. At $24 \mathrm{hrs}$, HSPG and SYN1 returned to values close to baseline (Figure 1).

The baseline HSPG correlated with systemic vascular resistance index (rho $=$ $-0.55 p=0.004)$, postoperative cardiac in$\operatorname{dex}(r h o=0.43-0.46, p=0.03)$, pulse pressure variations (rho $=-0.76, p=0.003$ ), and glucose concentration $(r h o=-0.50, p$ $=0.02$ ).

The baseline NT-proBNP demonstrated weak correlation with HSPG concentration at $6 \mathrm{hrs}$ after surgery $(r h o=0.42, p=$ 0.04) (Figure 2).

In addition, the baseline HSPG concentrations below $7.72 \mathrm{ng} / \mathrm{mL}$ predicted postoperative hyperlactataemia ( $\geq 2 \mathrm{mmol} / \mathrm{L}$ ) with AUC 0.75 , sensitivity $100 \%$ and specificity $58.3 \%(p=0.02)$ (Figure 3 ).

The values of HSPG at all stages and the baseline SYN1 concentration correlated with duration of mechanical ventilation (rho $=0.46-0.49, p<0.02)$.

\section{Conclusions}

At the selected perioperative time-points, the endothelial glycocalix system demonstrated relatively minor shedding to the elective on-pump cardiosurgical interventions and moderate associations with haemodynamics, metabolic response, and the duration of respiratory support.

\section{Acknowledgements}

We appreciate an invaluable assistance of the personnel of the cardiosurgical ICU, City Hospital \# 1 n. a. E. E. Volosevich (Arkhangelsk). In addition, the authors thank for the help of Drs. T. V. Chernova, M. M. Sokolova, E. V. Fot, and A. A. Smetkin.

\section{References}

Pesonen E, Passov A, Andersson S et al. Glycocalyx degradation and inflammation in cardiac surgery. J Cardiothorac Vasc Anesth 2018. doi: 10.1053/j.jvca.2018.04.007. [Epub ahead of print]

Chappell D, Bruegger D, Potzel J et al. Hypervolemia increases release of atrial natriuretic peptide and shedding of the endothelial glycocalyx. Crit Care 2014; 18: 538. 